\title{
A GUIDE FOR ENTERPRISE APPLICATION ARCHITECTURE DEPLOYMENT
}

\author{
Tiko Iyamu, Namibia University of Science and Technology, Windhoek, Namibia, connectvilla@yahoo.com
}

\begin{abstract}
In many organisations business applications are challenged in fulfilling their needs. This is attributed to lack of architectural guidance in the development, selection, and implementation of the applications. This study examined the trajectory of the challenges in the development, selection, reuse, and implementation of application in organisations. Three different organisations were used in the study. The dimension of change from the perspective of Structuration Theory was employed as lens in the analysis of the data. The aim of this study was to provide architecture guidance for applications, which is to support and enable the management of change, from applications' perspective, for competitiveness and sustainability. This is to reduce or eradicate complexities in the selection, implementation, and management of applications, in embracing business vision, goals and strategies. The study revealed how applications can be categorised, and the impact of applications' change on the organisation. The article presents an assessment model, and a matrix which could be used for both operational and strategic governance of applications in the organisations.
\end{abstract}

Keywords: Application Architecture, Enterprise, Change, Deployment, Structuration Theory

\section{INTRODUCTION}

Applications are developed and implemented in organisations primarily to address business needs, and to provide competitive advantage. According to Aerts et al. (2004), the capacity of modern enterprises to compete depends hugely on business application. As a result, governance factors in the development, selection, reuse, and implementation of applications are critical. Woods and Rozanski (2010) argued that there hardly regularity in the application implementation. Unfortunately, the enactment of governance factors is not always as easy as it is sometimes claimed. Applications in organisations do sometimes encounters challenges, such as integration, compatibility, and manageability. This results to cost prohibitive, and affects response time to rapid changes in business' needs.

Applications are often grouped into categories, mainly to classify their functionalities and technical specifications, so as to understand and provide appropriate governance. Some of the groupings include business applications, and development environments. Some examples of business applications are enterprise resource planning (ERP), frontend application, operating systems application, and web-based applications. Application environment consist of various technological artefacts, such as J2EE (Kessler, 2005).

The rapid change to business' needs and the evolutions of technology continue to pose challenges to the organisation that relies on applications for their processes and activities. Shan and Hua (2006) argued that to fulfil ever-growing business needs, more complex, flexible, scalable, and extensible applications are needed. As a result of the challenges, some organisations employ enterprise application architecture (EAA) in addressing the challenges that are posed and encountered in the development, selection, and reuse of applications. According to Wang, Zhou, and Jiang (2008), application architecture provides a blueprint which guide applications' deployment, their interactions and relationship with the core business processes of the organization. The EAA is a domain of the enterprise architecture (EA), which focuses on governance and strategy aspect of applications. According to Tamm et al. (2011), EA covers both current and future states, and focuses on enterprise's business processes and IT systems, and their interrelationships.

The rational for developing and implementing EA might differ, from organisation to organisation. Harmon (2005) argued that EA is implemented primarily, as a base, to determine the enhancement of requirements, and to rationalize investments in capability development. The EA is intended to bridge the gap between the business and information technology (IT) units, in the organisations. Kang et al. (2010) suggested that EA could be used as a tool to align business and IT units in the organisation. As empirically revealed in Iyamu (2011,p.32), "simply defining 
the EA exposes gaps in business processes and strategy, information technology and systems strategy, and the relationship between Business and IT units of the organisation"

The development, selection, reuse, implementation, and overall governance of applications has continue to be challenging in some organisations, making case for studies that has been carried out in this area, over the years. The challenges may be attributed to factors, such as selection (appropriate "fit") integration, configuration and compatibility. They have been problematic in many organisations, causing them to avoid or abandon the deployment of some applications, thereby, impacting business processes and activities. Due to the challenges some organisations over-spend their budget during the implementation of applications. According to Li et al. (2009), the need for dynamicity, scalability and easy maintenance makes it complex and difficult to design, develop and maintain web applications.

This article presents systematic approach on how EAA is developed and implemented in organisations, focusing on the route and the change which occur from current to future states. The development and implementation of EAA provides significant differences on how applications co-exist, and explains how they are used and managed in organisations. The manifestations of governance on applications have impacts on the return on investment in the organisation, hence it require emphasis. The objectives and focuses of this article is in twofold, they are: to present, how EAA is developed and implemented distinctly; and using the dimension of change from the perspective of Structuration to understand how EAA facilitate change in both business processes and technology artefacts.

The remainder of this article is divided into seven sections. The first two sections present literature review on application architecture and the research methodology, respectively. In the third section, the data analysis is presented, and discussed. The fourth section presents the guide on the deployment of application architecture, followed by discussion in the fifth section. Finally, a conclusion is drawn.

\section{ENTERPRISE APPLICATION ARCHITECTURE}

Enterprise application architecture (EAA) defines how applications are designed, how they cooperate, where they reside, and how they are used, to support and enable business' needs. The EAA is therefore intended to provide governance for the development, selection, and implementation of applications. This is to enable and guide the integration and decision support of applications, as well as their transaction from the current to future states (Winter, 2001). According to Schekkerman (2004), the application component identifies, defines, and organises the activities that capture, manipulate, and manage the business information to support mission operations. Also, EAA is intended to enable a high level of distributed systems' integration, the reuse of systems' components, rapid deployment of applications, and high responsiveness to changing business and technology requirements. Postma (2003) argued that the application architecture supports a system designer to find the pieces of source code that should be changed by translating the architecture-level.

Another aim of the EAA is to enable and support the development and implementation of applications in a consistent and uniform manner. The EAA is often considered as a technology-based change of business processes and, an amalgamation of both business activities and technology artefacts. According to Winter (2001), EAA allows for documentation of most important applications and their relationships, as well as the rules that are used for creating and maintaining appropriate applications structure in organisations.

Some individuals and organisations understand EAA differently. As such, description helps to shape the scope of EAA. We view application architecture as the organiser of systems, and their components, including the relationships among the systems as they evolve. According Hafner \& Winter (2008), application architecture represents an aggregate, enterprise-wide model of logical functionality clusters (applications) as well as information flows, and control flows between applications. For the purpose of this book, EAA is defined as a collection of integrated information systems and its components, (purchased or custom-developed) required satisfying the organisational needs.

Enterprise architecture Frameworks, such as Gartner Inc. (Burke, 2007), The Open Group Architecture Framework (TOGAF), and The Zachman Framework, presents similar views on about the EAA, including the development and implementation (Wang, Zhou \& Jiang, 2008). From the EAA perspectives, the frameworks focus on governance, 


\title{
Issues in Information Systems
}

\author{
Volume 15, Issue II, pp. 450-463, 2014
}

planning and building blocks of applications. The frameworks are intended to assist organisations to develop and implement application architecture. The frameworks cover components such as data, functions, and network (Zachman, 1987).

Woods and Rozanski (2010) argued that there is disconnect between some of the activities which happen in the process of development and implementation of EAA. The disconnect manifests into technological mismatch and irregularity in the development, integration, reuse, and implementation of applications. EAA is considered as the focal point of an organisation's systems development, implementation and inventory. Shupe and Behling (2006), the application architecture describes the applications which are required to support and enable the business requirements, which could engineer change in the organisation.

Change which is effected by applications is of critical importance to many stakeholders, such as business managers, application architects and end-users. This is mainly because of the investment, value, and intended contribution of the applications to the organisation. As engineered by architecture, every application has a trajectory, whether it is an in-house Built, Preparatory or Open Source. According to Giddens (1984), trajectory is duality of change. Continually, the change in applications' lifecycle is informed by business and technical requirements.

Change is managed, governed and supported by architecture. For the benefit of the organisation, it is of utmost importance to understand the trajectory of each application, as governed by the architecture. This is necessary, primarily because of the potential implications, which could impact the return on investment. A manager from the business units is often the financial sponsor of the application, which is aimed to enable and support the organisational business processes and activities. The architect is the technical strategic custodian of applications in the organisation. Academics seek to contribute to the body of knowledge through continued research which ultimately benefit organisations.

\section{METHODOLOGY}

A survey was conducted in three different organisations, to understand why and how application architecture was deployed and whether it is in-house built or bought. The organisations included a Telecommunication company, a Financial institution, and a Government Administration.

Each of the three organisations deployed many applications in their environment. Table 1 depicts the format as well as the classification of the applications.

The dimension of social change, from the perspective of Structuration Theory (ST) was employed to examine why and how EAA is developed and implemented in organisations. Rose and Hackney (2002) argued that ST has a very important role, and it is very substantial to the development and use of technology in the organisations that deploy it. ST offers a subtle and detailed view of the social-technical action and interaction. Its analysis through the dimensions of change, and its associated components, such as people, process and technology could be very detailed and helpful in the development and implementation of EAA.

Change occurs in the process of development as well as implementation of EAA in organisations. Change is influenced by both technical and non-technical factors. The model, 'dimension of change' as provided by Giddens (1984), is used to understand the levels of change that occurs in circumstances, from the development to the implementation stages of the EAA. The dimensions of change model consist of four components as shown in Figure 1:

1. Origin - is the original source of the episode.

2. Type - is an indication of how extensive or intensive a change could be. In other words, how profoundly a series of changes disrupts or reshapes an existing alignment of institutions.

3. Momentum - refers to the rapidity at which change occurs.

4. Trajectory - defines the overall direction of change. 


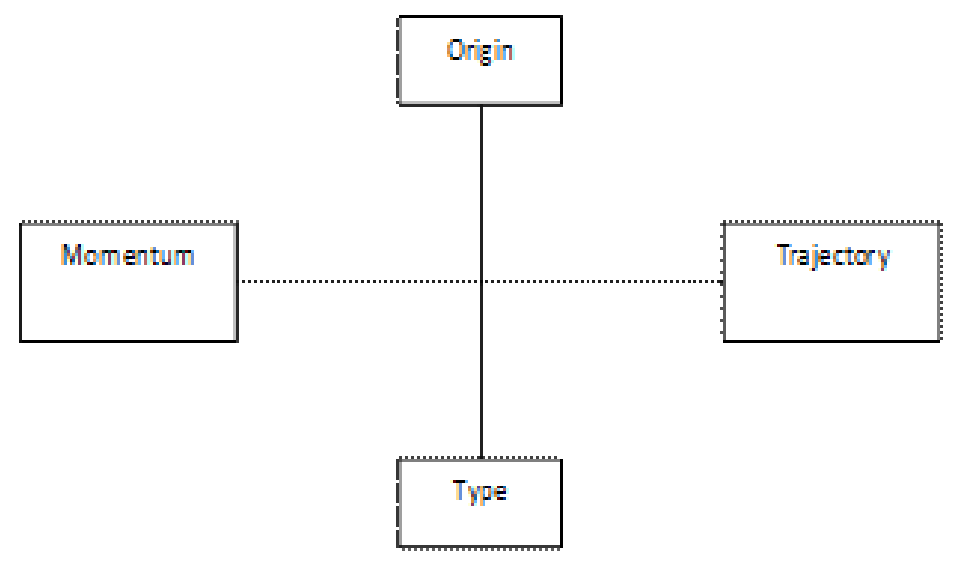

Figure 1: Dimensions of social change (Giddens, 1984)

According to Giddens (1984), the 'dimensions of social change' focus on two aspects of social practice: regularity and change. It takes into account the need to represent situations in different terms, from familiarisation to practitioners, and to explicitly consider information systems as an integral part of social practice.

\section{ENTERPRISE APPLICATION ARCHITECTURE}

Applications are sourced from in-house development, purchased off the shelf, or reused. The applications that are purchased are often categorised into Proprietary or Open Sources. Irrespective of the source, whether in-whole or inpart, the applications are should be guided by architecture.

Requirements gathering, development, and implementation are the main stages of the EAA. The decision to develop (in-house), buy or reuse an application is guided by EAA, which is driven by both technical and business requirements as defined by the organisation. The requirements often focus on sustainability and competitive advantage. The requirements influences and determine how the development is carried out. Subsequently, the development shapes and informs the implementation of EAA in the organisation's computing environment.

\section{Requirements gathering}

The EAA is based and shaped by both business and technical requirements, periodically. The business requirements are derived from the organisational processes, objectives, and strategy. Also, the business requirements provide the "why" (rationale) and "where" for EAA justification in the organisation. The technical requirements define the "what" and "how" applications could be deployed in the organisation. This includes middleware, operating systems, interoperability, and integration.

An additional requirement for the development and implementation of EAA is mainly to conduct "health" checks on key applications. The requirement is often based on factors, such as performance statistics, the number of incidents, and volume of support and maintenance. Other requirements include identification of the needed functionalities, strengths and opportunities, for the use and reuse of applications in the organisation.

The EAA primary characteristic is governance, which include principles, standards and policies. The governance guides both operational and strategic intents. The principles guide the selection, design, and implementation of applications, which include the integration components and business objects. The standards define the requirements that guide consistency and compatibility of applications and their components. The policies promulgate the rules and regulation, using the available resources to deploy applications in the organisation. 


\title{
Issues in Information Systems
}

\author{
Volume 15, Issue II, pp. 450-463, 2014
}

Other characters of the EAA are configuration and process. Configuration is used to provide contextual-based approach in the deployment of applications in the organisation's environment. The use of Process is to ensure procedural step-by-step action and transitioning in the deployment of applications in the organisation. The requirements for the development and implementation of EAA are gathered within scope and context as defined by the organisation. The articulation of requirements subsequently leads to the development of the EAA.

\section{Current State}

The current state is more on the inventory of applications which are deployed in the environment for the operationalisation of business logics, processes, and activities. This includes the components which are associated to each application; the relationships between the business processes which are enabled and supported by the applications; the interface between applications; information flow; and infrastructure patterns.

The application portfolio is preferably incorporated into the architecture repository in order to maintain links with the business processes and activities, as well as the business and technical requirements. The current state of applications is an evolving process, which is based on the definition, development, and implementation of EAA. Table 1 is a template which is designed to capture the information that is required from each application, as they continue to evolve, enable and support processes and activities in the organisation. The information is required by both the business and technical (particularly, the architects) personnel for decision making, in response to changing needs and requirements.

Table 1: Current State Identification

\begin{tabular}{|c|c|c|c|c|c|}
\hline $\begin{array}{l}\text { Application } \\
\text { Name (1) }\end{array}$ & $\begin{array}{l}\text { Business Processes } \\
\text { Supported (2) }\end{array}$ & Interface (3) & $\begin{array}{l}\text { Information } \\
\text { Required (4) }\end{array}$ & $\begin{array}{c}\text { Technologies } \\
\text { (5) }\end{array}$ & $\begin{array}{l}\text { Life cycle } \\
\text { (6) }\end{array}$ \\
\hline $\begin{array}{l}\text { Identification of } \\
\text { the } \\
\text { applications: } \\
\text { Name }\end{array}$ & $\begin{array}{l}\text { Clarification of the } \\
\text { business } \\
\text { applications as they } \\
\text { support business } \\
\text { processes; complete } \\
\text { with relationships. }\end{array}$ & $\begin{array}{l}\text { The interface } \\
\text { between } \\
\text { applications; } \\
\text { and between } \\
\text { application } \\
\text { and data. }\end{array}$ & $\begin{array}{l}\text { The database or } \\
\text { file system that } \\
\text { the applications } \\
\text { require to carry } \\
\text { out its functions. }\end{array}$ & $\begin{array}{l}\text { The } \\
\text { technology } \\
\text { that supports } \\
\text { the } \\
\text { applications }\end{array}$ & $\begin{array}{l}\text { Life cycle } \\
\text { and release } \\
\text { version of } \\
\text { the } \\
\text { application. }\end{array}$ \\
\hline
\end{tabular}

In EAA, the current state of applications is important in defining the strategic (future) direction. Some of the important factors are that it helps to avoid duplication, and to identify gaps.

\section{Existing Application}

Whether it is in-house developed, bought or reuse, organisations implement various applications in their environments. Table 2 depicts the format as well as the classification of applications in organisations. The applications are deployed for various reasons, and in different areas of functionalities. For example, the business applications, which support the organisation for competitiveness, are enabled by technical applications. The development, integration, reuse, and implementation of the applications are guided by governance.

The business applications include human resource (HR), Billing, Sale, Office Process (such as Word-processing and spread-sheet) and Workload Management (such as Work Flow). The Operating Systems, Middleware, Web Browser and Database are classified as technical applications. Governance includes rules and regulations, within which applications are developed and implemented, as well as enabled. Both business and technical applications depend on each other to fulfil the organisation's need. The dependencies make understanding of the business and technical requirements critical. Hence it is important to make use of a lens, so as to have a deeper view of the requirements in the development and implementation of the EAA. The dimensions of social change, was employed to examine and understand how EAA is developed and implemented in organisations.

\section{EAA Development}

EAA is fundamental to strategic planning, systems design, software development, hardware deployment, and the production and reproduction of multiple systems with differentiated functionalities and logics. The decision to employ an in-house built, to purchase from the shelf, or to reuse an existing application is based on how the architecture is developed. The development is therefore critical for competitive advantage. This is primarily because 
it has an influence and impact on return on investment, architectural fit of individual application, and co-existence of applications.

Table 2: EAA Development

\begin{tabular}{|c|c|c|c|c|}
\hline Planning & $\begin{array}{c}\text { Analysis \& } \\
\text { Design }\end{array}$ & Programming & Middleware & Repository \\
\hline $\begin{array}{l}\text { Application } \\
\text { used for } \\
\text { Projects } \\
\text { Planning. } \\
\text { E.g. } \\
\text { Microsoft } \\
\text { Project }\end{array}$ & $\begin{array}{l}\text { Application } \\
\text { used for } \\
\text { design and } \\
\text { analysis, such } \\
\text { as Modeling } \\
\text { Tools, and } \\
\text { Case Tools }\end{array}$ & $\begin{array}{l}\text { The programming } \\
\text { languages, Such as .Net, } \\
\text { C++, Java, HTML, for } \\
\text { development of } \\
\text { applications, such as } \\
\text { Front-end (client server } \\
\text { and web based). }\end{array}$ & $\begin{array}{l}\text { Application used mainly } \\
\text { for interfacing between } \\
\text { applications; application } \\
\text { and data; and between } \\
\text { data. Some of them } \\
\text { include ADO, SDE, } \\
\text { ODBC, and PL SQL. }\end{array}$ & $\begin{array}{l}\text { The repository } \\
\text { application includes } \\
\text { Visual Source Safe, } \\
\text { Component Manager, } \\
\text { and Oracle. }\end{array}$ \\
\hline
\end{tabular}

EAA development is the master plan for the deployment, support and maintenance of applications, in that, it considers both the current and the future states of the organisation. The development is driven by the requirements of the organisation, as discussed in the section above. Also the development of EAA is the procedural categorization of artefacts which are involved in the deployment of applications. Table 2 provides an example of the artefacts. The development influences the implementation of EAA.

\section{EAA Implementation}

EAA is implemented through governance, which includes principles, standards, configurations, processes, and policies. The EAA is intended to provide the means through which adaptive business applications could be supported, maintained, and managed, which is achieved through its implementation. The EAA also drives the introduction of new initiatives for various reasons, such as enabling of processes, sustainability and competitive advantage. The rational focuses on function, scalability, compatibility, and interoperability, periodically.

The implementation of EAA encompasses documentary of inventory, portfolio of events, and activities of applications in the organisation. The events and activities codify organisational functional requirements, and provide process engineering for competitiveness. The inventory involves documentation of obsolete, current, and strategic state of applications. This assists the organisation to assess the state of affairs, drive competitive advantage, as well as return on investment. The application portfolio is a representation of the functionality, which are not satisfied by the current applications, but required to fulfil both business and technical requirements.

The business requirements enable the business processes and activities, while the technical requirements provide guidance for the selection and deployment of technical applications, which are aimed at supporting and enabling business applications in the organisation. Examples of technical applications are presented in Table 2. The Table presents information and analytic requirements for enabling enterprise business strategies. The business applications are classified into many categories, they include Billing, Human Resource (HR), Sales Management, Accounting, Communication, and Collaboration. Each of the categories has numerous application products, through which change are also effected.

\section{IMPACT OF CHANGE}

In line with the definition that is provided above, EAA logically consist of principles, standards, and models that are derived from organisational business and technical requirements. The principles, standards, and models of the EAA include:

1. guides the engineering of the organisation's information systems;

2. allow applications to integrate and coexist in the same platform; and

3. applies and enables rapid change in the organisation's business processes. 
The interpretation of the rules creates signification and symbolic meaningful systems that provide ways for architects to develop and implement EAA in the manner that they deem fit. The architects reflexively apply their stocks of knowledge, as well as information that they gathered from their communication with other stakeholders, such as their direct clients, and colleagues.

The dispensability of technologies and increased momentum of competition amongst organisations inevitably enables change to take place by technology artefacts and business processes. EAA addresses this need by providing a strategic context for the evolution of the IT systems in response to constantly changing needs of the business environments.

Applications are often modified revitalised based on either technical or business requirements, or both. Modification of existing application is based on future functionalities, which results from change in processes and activities. This is enabled and supported by requirements, which guides the conduct of "health" checks on applications. The requirements are based on factors, such as performance statistics, the number of incidents, and the volume of maintenance and support.

As shown in Figure 2, the dimensional change of EAA involves dependency and interrelated processes and activities. The figure depicts a top-down flow of the processes, and how EAA can distinctly be developed and implemented in organisations. The events which are engineered by the EAA, changes the current situation from transitioning to desired state. Change does not necessarily mean replacement, and certain artefacts are reused within the ambit of the governance.

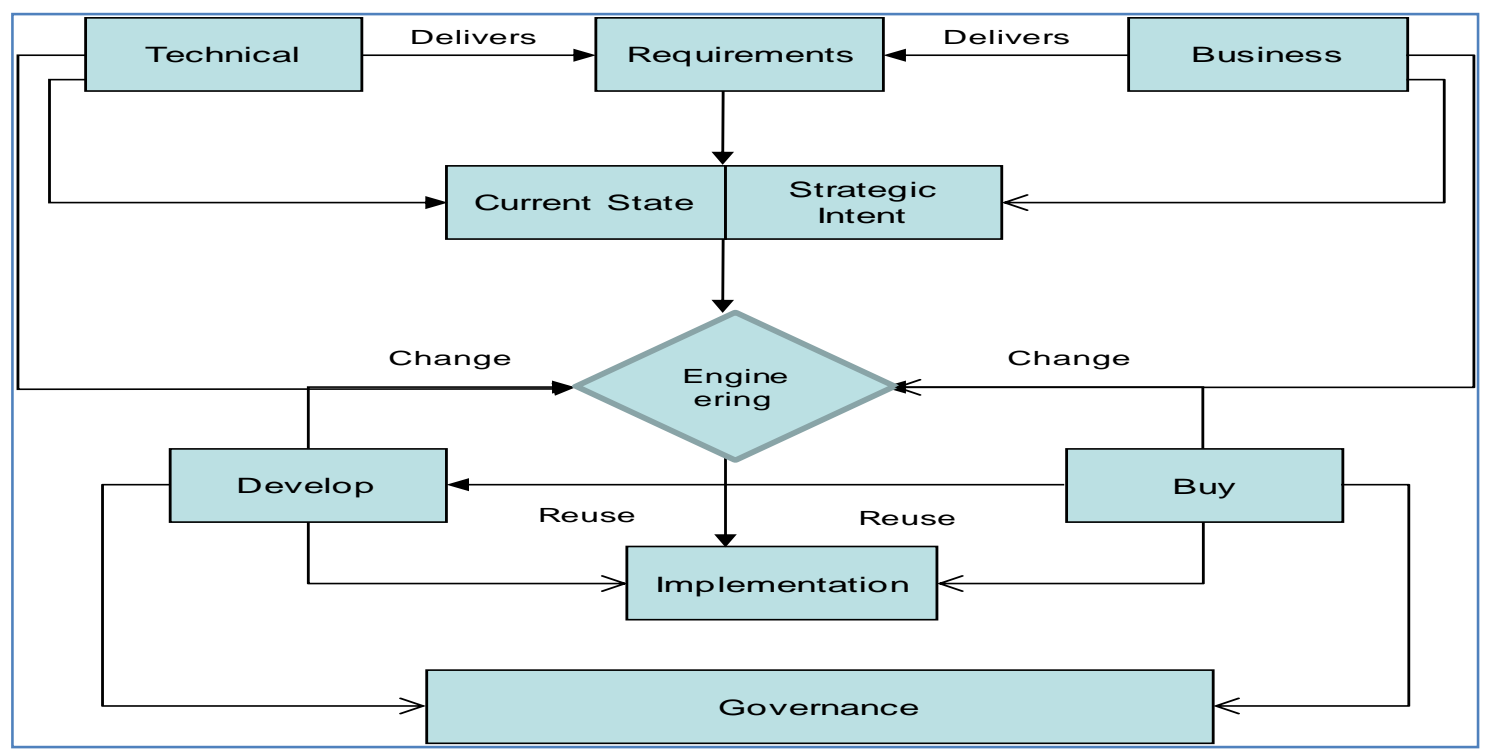

Figure 2: The Dimension of EAA Change

Each application is guided by both business and technical requirements. The architecture further helps shape the requirements, such as the formulation of the governance for its selection, deployment, support and maintenance. The components of dimension of social (Giddens, 1984), are discussed in relative to EAA:

\section{Origin: Architectural Requirements (ARs)}

EAA is problematized by a focal actor, based on the business requirements. The requirements are unique and original, based on their specific rational and articulations, from organisation to organisation. The business requirements are intended to provide a clear understanding of the goals and future of the organisation, for competitiveness. Otherwise, lack of formal, articulated, and clear requirements could manifest and create gaps. The requirements define and determine the organisational drivers for the business strategies, and value-chain (process and activities which are context-based) being pursued at the time. 
EAA starts by identifying the business-drivers and technical requirements. Based on the drivers and requirements, EAA focuses on providing support, direction and priority on individual and coexistence of applications in the environment. The organisational requirements provide the scope, boundary for the development and implementation of EAA. The EAA is intended to engineer, and re-engineer the business processes and activities, for sustainability, competitive advantage, through applications. Bottom-line is that the requirements are the determinant factors and the EAA is the change agent. The dimension in which change occurred has influence and impact on the output and performance of the organisation, wholly or partially.

Also, requirements help to conduct "health" checks on applications as change continues to occur, overtime. The checks are primarily aimed to identify deficiencies and gaps which exist within the business processes and activities. Decisions are made to change the situation, either through re-engineering or replacement, depending on the type and nature of the checks.

\section{Type: Status in the organisation}

Competitiveness is a determinant factor on the type, whether it is extensive or intensive nature of change within the organisation. Based on the type of change that is required, applications are employed. The EAA help to shape and reshape the deployment of applications, particularly to eliminate or reduce complexity, and foster return on investment.

Applications are deployed for unique aims and objectives, to produce and reproduce logics, processes and activities of the organisation. This is initiated by the organisational drivers, overtime and space, primarily to increase the value chain of the organisation. Applications are categorised into two main status types, current (operational) and future (strategic). The status, whether current or strategic has a change impact on shaping and reshaping the competitive advantage of the organisation, through applications, and as defined and guided by the architecture.

\section{APPLICATION ARCHITECTURE: ENABLING STRATEGIC DIRECTION}

EAA is intended to enable strategic direction of applications in the organisation. It enhances inventories through context-based models. The models define the relationships amongst applications, requirements (business and technical) dependencies, supported business processes and activities, and required infrastructure patterns.

The current state is evolved through planning and assessment, leading to strategic and technical fits of applications within the computing environment. Both strategic and technical fits are continually assessed. Strategic fit is assessed based on the applications' contribution to business value, as defined by the architecture, and driven by both technical and business requirements. Technical fit is assessed based on the applications' adherence to the architectural design principles and technology standards. The assessment model enables users and managers to measure applications' needs in accordance to the four categories of prioritization, as shown in Figure 3. Strategic direction determines the periodic use of the applications.

\section{Momentum: Prioritisation Engineered by Change}

The rapidity at which change in applications occurs in the organisations is based on business requirements. The rapidity of applications' change ignites how criteria are extracted to give direction and priority to each of the business processes and activities, which are enabled and supported by applications in the organisation. Table 2 is a template which could be used to extract requirements from the organisational strategy, and proceed to the detailed features of the applications. The momentum of the applications determines how support and maintenance are prioritised and provided.

The criteria and prioritisation, as defined in Table 3 is intended to reduce or eliminate much of the guesswork and inconsistency that might arise in the course of interpreting the impact of strategic applications on processes and activities, and the priority that should be placed on them. Also, the Prioritisation Matrix, Table 3 is aimed at evaluating and managing applications deployment that will persist in the face of rapid change from the organisational requirements. It is a mechanism used to identify and resolve conflicts, as well as building consensus on strategic directions within the shortest possible time. 


\section{Issues in Information Systems}

Volume 15, Issue II, pp. 450-463, 2014

As shown in Table 3, the decision to deploy, use and maintain applications in organisations is based on priorities. Prioritisation of applications is a building block process. Matrix is required on the need for applications in the organisations. It contextualises the current and future states, including the operationalization and possible opportunities during the deployment of applications. The measurement scores as defined by the matrix are totalled to assist the prioritisation process for decision making. The increasing number of the total score indicates the values of the application to the organisation's needs. The lower the total number of the score, the less attention is required or given to the application.

Table 3: Application Prioritisation Criteria

\begin{tabular}{|l|l|l|l|l|l|}
\hline Category & 5 - Strategic & $\mathbf{4}$-Operational & $\mathbf{3}$ - Tactical & 2-Managed-out & 1-Optional \\
\hline 5 - Requirements & & & & & \\
\hline $\begin{array}{l}\text { 4- Strategic } \\
\text { objectives }\end{array}$ & & & & & \\
\hline $\begin{array}{l}3 \text { - Operational } \\
\text { necessity }\end{array}$ & & & & & \\
\hline $\begin{array}{l}2 \text { - Opportunity } \\
\text { 1 - Nice to have }\end{array}$ & & & & & \\
\hline
\end{tabular}

The Scores from the prioritisation matrix are calculated with associated values. The measurement score determine the level of application's prioritisation in the organisation. The measurement scores are grouped in ranges of five, as described below:

25-20: This is considered as most critical to the organisation. It is needed as soon as it is practical. It is expected to be of high value to the organisation. It is considered to be driven by the strategy of the organisation.

$19-15$ : This is the second highest level of prioritization. It is considered to be very important to the organisation. It could be used as an indicator for sustainability and competitive advantage. As such, it does require high attention.

14-10: This is middle ranged indicator for prioritisation of applications. At the range, the application is considered to be essential to the processes and activities of the organisation. It is necessarily required to improve on efficiency and effectiveness of the operations of the organisation.

9 - 5: At this range, the application is required only for continuity purposes. It is assessed to have marginal improvement to the processes and activities of the organisation. Applications which are within this range are often required for purposes, such as, by law, regulations or directive.

$0-4$ : This is the lowest of the priorities ranges. At this range, the applications are considered to have little or no impact to the organisation's processes and activities. It could be considered optional.

The criteria for prioritization allow the nature and degree of failure to be examined and understood by the stakeholders. The criteria as tabulated in Table 3 are aimed to facilitate change to evolving requirements. The use of the criteria and prioritisation model make decision more discrete, consistent and comprehensive in the execution of EAA.

\section{Prioritazation Process}

The aforementioned Prioritisation Criteria is the responsibility of both the architects and information systems and technology (IS/IT) managers:

1. IT/IS Managers identify and document the requirements for each of the processes and activities, which are supported and enabled by applications in the organisation.

2. The architects define the architectural criteria for each of the processes and activities that are enabled and supported by each application. 
3. The architects provide options which are aimed at competitive advantage to the IS and IT managers for informed decision making.

4. In collaboration with the architects, the IS and IT Managers make decision on the prioritization of applications' deployment, support and maintenance. This is done in accordance with the business needs.

5. The decision is communicated to the IT Relationship Managers or Business Analysts, who drills down the communication and documentation to the various IT and business units' representatives, in accordance to their roles and responsibilities. The communication and documentation indicates the priorities of the applications.

6. The IS or IT Managers enforce the deployment of the prioritised applications. This includes the decision to develop, buy or reuse of applications.

7. A prioritised plan is put together to support, maintain, and manage the affected applications, within timeframe and budget.

\section{Build, Buy, Reuse}

EAA is an on-going, integrated collection of existing and planned information systems (applications and their components, purchased or in-house built) required to enable and support the ever-changing business requirements, consequent business processes, and information and technical requirements.

Every application, whether it is in-house built, purchased or reused, are aimed to add value to the organisation. The categories (build, buy or reuse) of applications are defined and guided by EAA. Figure 3 indicates the direction of each application, as they are employed in the organisations. The elements (directions) of the figure include reevaluation or reposition; maintain or evolve; phase out or replace; and development of application.

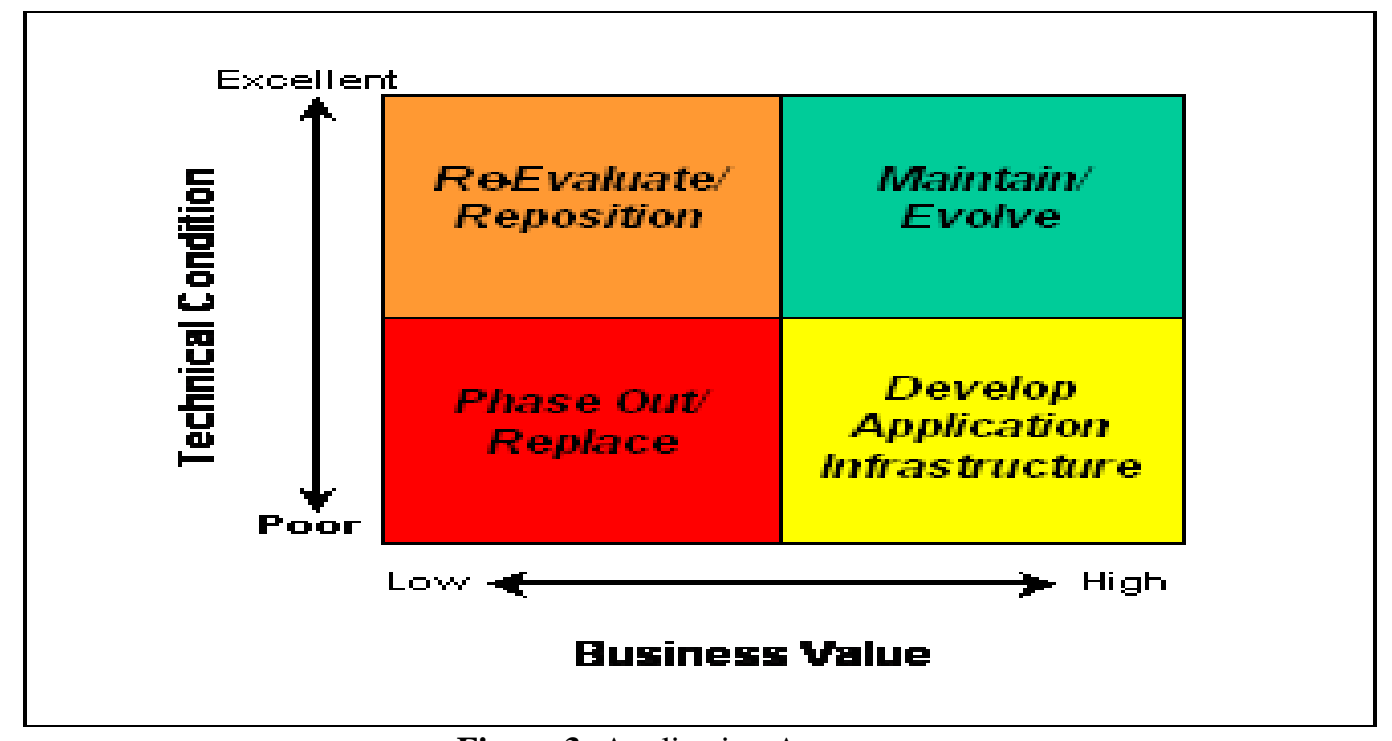

Figure 3: Application Assessment

The four elements of Figure 3 are discussed as follows:

1. Phase out/Replace. This indicates low business value (BV), and poor technical condition (TC). The applications that are in this category should be considered for replacement. However, some which include legacy or back-office applications may not be cost justifiable to replace in terms of return on investment. Thus taken into consideration, of the limited business value that it could add to the organisation for competitive advantage is of higher consideration and priority.

2. Re-evaluate/Reposition. This is with low business value (BV), but with excellent technical condition (TC). The applications that are in this category are often newly implemented. They are often architecturally fit. However, the scope was not properly defined, or was of silo-oriented design. As a 


\section{Issues in Information Systems}

Volume 15, Issue II, pp. 450-463, 2014

result, the significant business value becomes a challenge, or not easily achieved. The critical point is to identify and analyse the strengths, opportunities for use and reuse of these types of applications, or the integration of their components within the organisation's requirements.

3. Develop application infrastructure. This is of high business value (BV), but with poor technical condition (TC). These applications serve the business needs, and provide the organisation with significant sustainability and competitiveness. On the technical front, the applications create substantial problems to manage. This includes information flow, and integration with other applications. This could be addressed through a more adaptive application infrastructure (component-based, event-driven, n-tier, with message-based interfaces) as defined by EAA.

4. Maintain/Evolve. This is of high business value (BV), as well as of excellent technical condition (TC), to the organisation. Applications within this category are considered to deliver value, and they have been architected for adaptability in the environment. The architecture is designed to ensure both high business value and excellent technical condition when optimising the application portfolio to accommodate continued requirements changes.

The EAA is developed and implemented to enforce change by moving the existing applications towards strategic direction. The architecture provides a process for migration by taking into account strategic factors such as business and technical requirements; return on investment; and "technology fit" of existing and planned information systems and technologies.

The assessment of application strategic direction leads to necessary actions, which are produced and reproduced overtime and space. Some of the actions include the following:

a. Analysis of technical requirements against the technologies. This is to uncover any deficiency, and additional infrastructure capabilities that may be required.

b. Reconcile the application and infrastructure projects which are needed to satisfy the results of the previous steps. This is a synchronisation effort of joint-migration planning of both the technical and business applications. Applications planning and deployment are prioritised in accordance to the results of the assessment.

The migration plan of each application requires documentation at a high-level timeline, within priorities, and for dependencies purposes. This is intended to incorporate all projects that are related to applications in the organisation.

\section{Trajectory: Governance}

EAA employs governance which defines the overall direction of application change within an organisation. EAA is a process that provides models and blueprints of current and future states. This is used to provide a roadmap to actualising business vision and objectives, through its requirements. The governance includes architectural principles, policies and standards.

\section{a. Architectural Principles}

The architectural principles set the boundary and limit of the operandi in the deployment (development and implementation) of applications in the organisation. The principles provides configuration standard, which guides technology products. Within the principles, technologies are configured to deliver a reusable building block of technical infrastructure, such as web and application servers. The design, development, and implementation of applications are evaluated for consistency and uniformity purposes, within the principles that are formulated.

The architectural principles are formulated within comprehension and necessity, which provides guidance for applications' deployment in the organisation. This is not necessarily a prerequisite to halt applications' deployment. The bases for many principles are best practices, approaches that have consistently been demonstrated by diverse organisations, to achieving similar results. Therefore, the degree to which an organisation can formulate principles, which impact processes and activities is dependent on its ability to identify and apply best practices in each of its business areas. 
The principles lead to the formulation of policies, and are applied as guidance to the designers, developers, and implementers of the applications.

\section{b. Architectural Policy}

The architectural policy is a part of governance, which defines and promulgates what must be done, in adherence to the EAA. The policy is based on the organisational, and derived from the architectural principles. The policy guides against constraints and complexities. It helps to facilitates and manages change through governance, in the organisation. The governance also ensures that the information and processes which are involved in the design, development, and implementation of applications are protected, quality is maintained, and that competitive advantage is prioritised and pursued. Based on the policy, the architectural standards of the EAA are reached.

\section{c. Architectural Standards}

Change to organisation's goals, combined with other unyielding competitive forces, such as environmental trends, can cause tremendous confusion and complexity in the organisation. This is one of the motivations for the architectural standards. It provides a stabilizing environment, of consistency, uniformity, and continuity.

As in many cases, definitions artefacts are sometimes different. We define Architectural Standardisation as, documented technical specifications, and requirement or criteria, which are intended for consistent and unification, used use as rules, and guidelines, and to ensure that materials, products, processes, and services are fit for their purposes. The primary role of standards, from the EAA perspective is to organise applications, its components, deployment, and use. This includes rules which assist architects to identify common use of technologies, eliminate as much redundancy as possible, and improve on competitive advantage.

The EAA reflects on process orientation, development and operationalisation of deliverables of information systems and business processes. The importance and need to standardise events and artefacts continue to increase. This is mainly because standardisation assists to address complex and vital issues, such as selection, compliance, and evaluations of applications.

\section{DIMENSION OF ENTERPRISE APPLICATION ARCHITECTURE CHANGE}

The EAA involves a process of different dimension, from the requirements gathering to governance stages. The dimension engineer change in the organisation as the requirements and needs continue to evolve, and rapidly. Change process is intended to address identified business and technological challenges, and promote competitive advantage. For example, if the organisation vision changes, the resources including technology are refocused in order to achieve that change.

EAA is designed, developed and implemented to meet the changing needs of technology and business, through different dimensions. Change involves adaptations in practices, which include resources, know-how, and skills. Also, it is often the beliefs about what is important and valuable, within context and relevance, to the organisation. In addition, it requires the interaction, connectedness, and sharing of power across different components of the applications.

The dimension of change requires the development of an organisational capacity to respond to the changing needs and conditions. Typically, the goal is not mastery of a single innovation, but of on-going learning, and the development of collaborative work cultures, as defined by the architecture. Changing the application profile to meet the requirements of the organisation requires flexibility and collaboration. From the application perspective, the architecture addresses provide a shared view of how the business works, and what it works with, to the actors (stakeholders) who enrolled in the concept. 


\section{CONCLUSIONS}

The article presents EAA method that emphasizes placing organisational applications into context, and captures this context through the goals and vision statements of the organisation. The EAA is developed and implemented on the premises of change.

EAA is primarily to design and deploy applications in order to enable more effective operational practices for competitive advantage. To bring this about, the prevailing business paradigm must be questioned with goals, processes, and roles which are considered afresh in the light of new technological potentialities. Through the implementation of EAA, the IT and business units engage in an intensive learning experience, the former to develop a thorough understanding of the business domain, the latter to reflect on current practices and to acquire an understanding of the potential of IT to transform how work is done.

Thus, the primary reason for developing and implementing EAA is therefore, to provide the technical foundation for an effective IT and business strategies. Hence it is posit that EAA has the additional ability to assist in the management of change, lifting the vision from simple questions of technology and attempting to embrace business vision, goals and strategies.

\section{REFERENCES}

Aerts, A., Goossenaerts, J., Hammer, D. and Wortmann, J. (2004) Architectures in context: on the evolution of business, application software, and ICT platform architectures, Information \& Management, 41, pp. 781-794.

Burke, B. (2007). The Role of Enterprise Architecture in Technology Research, Gartner Inc. http://gartner.com/technology/research.jsp (Accessed 14 April 2010).

Giddens, A. (1984). The Constitution of Society: Outline of the Theory of Structuration, Cambridge, UK; John Polity Press.

Hafner, M. and Winter, R. (2003) Processes for Enterprise Application Architecture Management, in the Proceedings of the 41st Hawaii International Conference on System Sciences, pp. 396-396. IEEE Computer Society, Washington DC.

Harmon, K. (2005). The 'systems' nature of enterprise architecture, IEEE International Conference on Systems, Man and Cybernetics.

Iyamu, T. (2011). Institutionalisation of the Enterprise Architecture: The Actor-Network Perspective. International Journal of Actor-Network Theory and Technological Innovation, vol. 3, no. 1, pp: 27 - 38.

Kang, D, Lee, J. and Kim, k. (2010) Alignment of Business Enterprise Architectures using fact-based ontologies, Expert Systems with Applications, vol. 37, no. 4, pp. 3274-3283.

Kessler, J. (2005) Impact of Insurance Application Architecture on relaunching software development environment" in the Proceedings of the International Conference on Computational Intelligence for Modelling, Control and Automation, and International Conference on Intelligent Agents, Web Technologies and Internet Commerce.

Klein, H. \& Myers, M. (1999) A set of principles for conducting and evaluating interpretive field studies in Information Systems, MIS Quarterly, vol. 23, no. 1, pp. 67 - 93.

Law, C., Henderson, A. \& Ahrens, J. (2001). An Application Architecture for Large Data Visualization: A Case Study, IEEE.

Li, J., Chen, J, \& Chen, P. (2009) Modeling Web Application Architecture with UML, IEEE, pp. 265-274.

Postma, A. (2003) A method for module architecture verification and its application on a large component-based system, Information and Software Technology, 45, pp. 171-194.

Rose, J. \& Hackney, R. (2002) Towards a Structurational Theory of Information Systems: a Substantive Case Analysis," proceeding of the $36^{\text {th }}$ Hawaii International Conference on System Sciences, Track 8, vol. 8, pp. 258, USA; Washington.

Schekkerman, J. (2004) How to survive in the jungle of Enterprise Architecture Frameworks, Victoria: Trafford.

Shan, T. C., \& Hua, W. W. (2006). Solution architecture for n-tier applications. In Services Computing, 2006. SCC'06. IEEE International Conference on (pp. 349-356). IEEE. 


\section{Issues in Information Systems}

Volume 15, Issue II, pp. 450-463, 2014

Shupe, C., \& Behling, R. (2006). Developing and implementing a strategy for technology deployment. Information Management Journal, vol. 40, np. 4, pp. 52-57.

Tamm, T., Seddon, P. B., Shanks, G., \& Reynolds, P. (2011). How does enterprise architecture add value to organisations?. Communications of the Association for Information Systems, 28.

Wang, X., Zhou, X., \& Jiang, L. (2008). A method of business and IT alignment based on enterprise architecture. In Service Operations and Logistics, and Informatics, 2008. IEEE/SOLI 2008. IEEE International Conference on (Vol. 1, pp. 740-745). IEEE.

Winter, R. (2001). The Current and Future Role of Data Warehousing in Corporate Application Architecture, In the Proceedings of the 34th Hawaii International Conference on System Sciences.

Woods, E. \& Rozanski, N. (2010) Unifying Software Architecture with its Implementation, in the Proceedings of the Fourth European Conference on Software Architecture, The ACM Digital Library.

Yin, R. K. (2009) Case Study Research, Design and Methods, $4^{\text {th }}$ ed., California, Newbury Park; Sage Publications.

Zachman, J.A. (1987). A framework for information systems architecture, IBM Systems Journal, vol. 26 no.3, 1987, pp. 276-292. 